\title{
Different faces of discrimination: perceived discrimination among homeless adults with mental illness in healthcare settings
}

Anna Skosireva ${ }^{1}$, Patricia O'Campo ${ }^{1,2}$, Suzanne Zerger ${ }^{1}$, Catharine Chambers ${ }^{1}$, Susan Gapka ${ }^{3}$ and Vicky Stergiopoulos ${ }^{1,4^{*}}$

\begin{abstract}
Background: Research on discrimination in healthcare settings has primarily focused on health implications of race-based discrimination among ethno-racial minority groups. Little is known about discrimination experiences of other marginalized populations, particularly groups facing multiple disadvantages who may be subjected to other/ multiple forms of discrimination. Objectives: (1) To examine the prevalence of perceived discrimination due to homelessness/poverty, mental illness/alcohol/drug related problems, and race/ethnicity/skin color while seeking healthcare in the past year among racially diverse homeless adults with mental illness; (2) To identify whether perceiving certain types of discrimination is associated with increased likelihood of perceiving other kinds of discrimination; and (3) To examine association of these perceived discrimination experiences with socio-demographic characteristics, self-reported measures of psychiatric symptomatology and substance use, and Emergency Department utilization.
\end{abstract}

Methods: We used baseline data from the Toronto site of the At Home/Chez Soi randomized controlled trial of Housing First for homeless adults with mental illness $(n=550)$. Bivariate statistics and multivariable logistic regression models were used for the analysis.

Results: Perceived discrimination related to homelessness/poverty (30.4\%) and mental illness/alcohol/substance use (32.5\%) is prevalent among ethnically diverse homeless adults with mental illness in healthcare settings. Only $15 \%$ of the total participants reported discrimination due to race/ethnicity/skin color. After controlling for relevant confounders and presence of psychosis, all types of discrimination in healthcare settings were associated with more frequent ED use, a greater - 3 - severity of lifetime substance abuse, and mental health problems. Perceiving discrimination of one type was associated with increased likelihood of perceiving other kinds of discrimination.

Conclusions: Understanding the experience of discrimination in healthcare settings and associated healthcare utilization is the first step towards designing policies and interventions to address health disparities among vulnerable populations. This study contributes to the knowledge base in this important area.

Trial registration number: This study has been registered with the International Standard Randomized Control Trial Number Register and assigned ISRCTN42520374.

Keywords: Racial discrimination, Social discrimination, Homeless persons, Prejudice, Racism, Healthcare, Adult, Canada, Mentally III persons, Substance-related disorders

\footnotetext{
* Correspondence: StergiopoulosV@smh.ca

${ }^{1}$ Centre for Research on Inner City Health, Li Ka-Shing Knowledge Institute,

Keenan Research, Centre, St. Michael's Hospital, Toronto, Canada

${ }^{4}$ Department of Psychiatry, University of Toronto, Toronto, Canada

Full list of author information is available at the end of the article
} 


\section{Background}

Discrimination can be defined as the prejudicial and/or distinguishing treatment of an individual based on their actual or perceived membership or certain characteristics, such as race, ethnic origin, gender, sexual orientation, age, immigration status, income, medical condition or mental or physical disability. It can be conveyed through opinions, attitudes, and behaviours, and can be measured by documenting objective events or relying on subjective perceptions of events [1].

Discrimination can have a significant impact on the lives of those affected. The stress of perceived discrimination negatively affects mental and physical health, and may increase the likelihood of risky health behaviors [2-6]. Perceived discrimination is shown to have a negative impact on help seeking, access to care, poverty, and social marginalization [7]. Within healthcare settings, discrimination by healthcare providers can function as a key barrier to obtaining needed services, resulting in avoidance or delays in treatment seeking, underdiagnosis and mistreatment, nonadherence with or discontinuation of treatment, and poor treatment outcomes [8-11]. A recent Canadian review of discrimination in healthcare noted that negative health outcomes were evident "even under conditions of equal access to medical care" [12] p.19.

Recent meta-reviews of discrimination research from the U.S. highlight that the preponderance of studies to date focus on race- and gender-based discrimination $[13,14]$. Yet for certain marginalized populations, discrimination from other defining group characteristics - such as homelessness, poverty, mental illness, and substance use - may have an equal if not greater impact than discrimination due to race or gender [15-18]. In fact, despite the weighty, negative impacts of discrimination in healthcare settings, surprisingly little is known about the different kinds of discrimination that marginalized individuals encounter, besides those due to race. Individuals who belong to several disadvantaged groups may suffer aggravated and specific forms of discrimination in consequence. Furthermore, researchers have noted the potential additive effects of stigma and discrimination, though this is less frequently explored [19].

Homeless persons with mental illness are among the most marginalized patient groups. Adults experiencing homelessness tend to report high levels of unmet health needs $[20,21]$, due in part to numerous access barriers, including perceived discrimination in healthcare settings [22]. Stigma and discrimination due to mental illness can have more devastating and long-lasting effects on the individual than the mental disorder itself [23] and perpetuate a cycle of impoverishment and disability $[24,25]$. While the link between homelessness and mental illness is well documented [25], the experiences of discrimination among homeless people with mental illness within healthcare settings are not well known or understood [10].

This study aims to address some of these gaps in the literature by exploring experiences of discrimination in healthcare settings in an ethnically diverse sample of homeless adults with mental illness in a large urban centre. We used the Aday Framework for Studying Vulnerable Populations to guide this work [26]. According to this framework, vulnerable populations are defined as those groups of individuals who have a greater-than-average risk of poor health by virtue of their marginalized social characteristic(s) such as race/ethnicity, gender, age, socioeconomic status, mental health, or (and) disability [26]. Perceived discrimination was assessed across three domains: (i) homelessness and poverty; (ii) mental health, alcohol and drug-related issues; and (iii) race or ethnicity or skin color. We explored the prevalence of perceived discrimination in the previous 12 months and its association with socio-demographic characteristics, self-reported measures of psychiatric symptomatology and substance use, and Emergency Department (ED) utilization. Finally, we examined whether perceiving certain types of discrimination was associated with increased likelihood of perceiving other kinds of discrimination in this sample of homeless adults with mental illness who experience multiple disadvantages.

\section{Methods}

\section{Study sample}

This study used data from the Toronto site of the At Home/Chez Soi project, a randomized controlled trial of Housing First for homeless persons with mental illness in five cities across Canada. Details of the Toronto site recruitment and study design have been described previously [27]. Eligibility criteria for the randomized controlled trial included: (1) legal adult status ( $\geq 18$ years old); (2) absolute homelessness or precarious housing (for definitions see [28]); and (3) presence of a mental illness with or without a co-existing substance use disorder, as determined by the MINI International Neuropsychiatric Interview at study entry [29]. Respondents were excluded from the study if they were receiving intensive case management or assertive community treatment at the time of recruitment, had no legal immigrant or refugee status in Canada, or were relatively homeless (individuals who inhabit spaces that do not meet basic health and safety standards, such as living in overcrowded or hazardous conditions, or couch surfing) ${ }^{\mathrm{a}}$. In addition, this study excluded individuals for whom interviewers gave poor subjective confidence scores that indicated unreliable responses. Our final study sample included 550 individuals.

All participants gave written informed consent for the study. Structured interviews were conducted by trained 
research assistants. The study has been registered with the International Standard Randomized Control Trial Number Register (ISRCTN 42520374) and was approved by the Research Ethics Board at St. Michael's Hospital in Toronto, Canada.

\section{Measures \\ Dependent variables}

Outcome variables measured perceived discrimination experiences in healthcare, and were adapted from the Toronto Street Health survey, developed for homeless participants [30,31]. Questions about perceived discrimination covered a wide range of discriminatory perceptions. Respondents were asked: "Thinking specifically of all experiences you have had with healthcare visits in the last 12 months, have you ever felt that the doctor or healthcare staff you saw judged you unfairly or treated you with disrespect because of ..." and reported on various perceived experiences of discrimination, such as homelessness, poverty, mental health or substance use problems, ethnicity, race and skin color. The responses for each variable were coded as "yes" or "no". Experiences of perceived discrimination were subsequently grouped into three categories based on conceptual relatedness and significant correlations between the variables within each domain. The three discrimination domains included: discrimination due to (1) homelessness or poverty (yes $=1$; no $=0$ ), (2) mental health, alcohol and drug-related issues (yes $=1 ;$ no $=0$ ), and (3) race or ethnicity or skin color (yes $=1$; no $=0$ ).

\section{Independent variables}

In light of conceptual understandings and prior research, our study controls for age, sex, race/ethnicity, income, and duration of homelessness. The self-report sociodemographic questionnaire in this study was based on the Demographics, Service Use \& Housing History questionnaire adapted from the 2006 Census of Canada [32], the Toronto Board of Education Student Census [33], and the Community Mental Health Evaluation Initiative [34]. Housing categories included living on the street, temporary/unstable residences $(<6$ months and unprotected tenancy rights), stable residences ( $>6$ months/no current plans to move and/or tenancy rights), emergency shelters/crisis housing, and institutions (e.g., detox facility, nursing home/long-term care facility, addictions treatment or recovery residential program, hospital, or jail). Homelessness was defined as currently having no fixed place to stay for more than seven nights and little likelihood of obtaining accommodation in the upcoming month or being discharged from an institution, prison, jail or hospital with no fixed address [28]. Duration of homelessness was dichotomized using a median split $(<3$ vs. $\geq 3$ years). The race/ethnicity variable included three categories: White, Black, and Other racial/ethnic minority, consisting of individuals with Asian, Middle Eastern, Aboriginal, Latin American, and mixed racial/ethnic background.

Service use was assessed by self-report. Having a regular medical doctor was assessed by asking: "Do you have a regular medical doctor? By regular medical doctor we mean a family doctor or GP who is familiar with you and your medical history". A variable on usual source of outpatient care was assessed by asking: "Is there a place that you usually go to when you are sick or need advice about your health?" Participants selected from a list of various inpatient and outpatient services. Presence of provincial health insurance was assessed by the question: "Do you have a provincial health card number?" Unmet needs were evaluated by asking: "In the past 6 months, was there ever a time when you felt that you needed healthcare but you didn't receive it?" These variables have been previously used by our team to assess barriers to accessing care among vulnerable populations.

Mental health symptoms were assessed by the Modified Colorado Symptom Index (CSI) [35]. The CSI includes 14-items that assess the presence and frequency of psychiatric symptoms within the past month on a 5-point ordinal scale [35-38]. A higher score indicates a higher level of psychiatric symptomatology. Internal consistency $(\alpha=0.90)$ of the modified CSI in this sample was similar to the value reported by Conrad et al. [37]. Missing values on the CSI $(8 \%)$ were replaced with average item scores for respondents who answered at least 9 of the 14 items. An overall score of 30 was set as a cutoff for clinically significant symptoms denoting the need for further psychiatric assessment [36-38].

Delusions and erroneous beliefs that are present in psychotic conditions may interfere with the individual's ability to think clearly, distinguish symptoms from reality, and relate to others, which may result in misinterpretation of experiences related to discrimination. Thus, presence of psychosis was used as a covariate (control variable) to account for the possible effect of psychosis on the perceived experiences of discrimination. Based on the interviewers' impressions and comments, the study excluded individuals who were believed to provide unreliable responses (e.g., due to a lack of cooperation or intoxication), effect of other sources of variation. Presence of a psychotic disorder was determined by DSM-IV criteria on the Mini International Neuropsychiatric Interview (MINI) 6.0 [39,40]. The MINI has demonstrated excellent inter-rater and test-retest reliability, and good validity against the Composite International Diagnostic Interview [41] and Structured Clinical Interview for DSM-IV-TR Axis I [42].

Severity of substance use problems was evaluated using the 5-item Substance Disorder Screener (SDScr) of 
the Global Assessment of Individual Need Short Screener (GAIN-SS). GAIN-SS offers a validated and standardized clinical and research assessment of alcohol and substance use disorders based on the DSM-IV $[43,44]$. The GAIN SDScr is composed of 5 items. Counts were generated for the number of lifetime substance use symptoms, with higher scores representing greater severity of substance use problems over the life course (in the past month, 2-12 months ago and 1 and more years ago). The counts were stratified into low (0 symptoms), moderate (1-2 symptoms), and high (3 or more symptoms) severity [43]. The reliability of GAINS SDScr in this sample was 0.90 .

The number of hospital emergency department (ED) visits in the past 6 months was used as a proxy for frequency of contacts with the healthcare system. Homeless people have substantially higher rates of ED use compared to the general population [45] and hospital EDs serve as the primary means of entry into the healthcare system for homeless people, who have limited access to primary care providers in many service contexts $[46,47]$. Therefore, ED utilization can provide useful proxy information about contacts and experience with the healthcare system. Number of ED visits was assessed by two questions: "In the past 6 months, have you been to a hospital emergency room?" and "Approximately how many emergency room visits did you have in total?".

\section{Analysis}

First, we conducted descriptive analyses to determine the overall prevalence of discrimination. Data analysis involved both univariate and multivariable logistic regression techniques. Variables that could be associated with perceived discrimination were selected a priori, guided by previous research and Aday's framework for studying vulnerable populations [26]. The following variables were considered as possible predictors of perceived discrimination: age (years/10), sex (male or female), race (White, Black, or other), monthly income $(<\$ 500$, $\$ 500-\$ 999$, or $\geq \$ 1,000)$, duration of homelessness $(<3$ or $\geq 3$ years), clinically significant psychiatric symptoms (CSI score: $<30$ or $\geq 30$ ), presence of psychotic disorder (MINI: yes or no), severity of lifetime substance abuse (GAIN SDScr: no/low, moderate, or high), hospital ED visits in the past 6 months (no visits, 1 visit, or $\geq 2$ visits). For pairs of highly correlated independent variables, only one was chosen; immigrant status (foreign born vs. Canadian born) was not included because it is significantly associated with race/ethnicity. Eight transgender/transsexual individuals were grouped with the "male" category to allow for cell counts above five in the bivariate analysis and to reflect the predominant male biological gender of these individuals. For the multivariable regression models, three domains of discrimination were used as dependent variables to evaluate the effect of a select group of predictor variables on the probability of expressing perceived discrimination. Variables that were associated with outcomes with a $P$ value of $\leq .20$ in the univariate analysis were simultaneously entered into multivariable logistic models. Presence of psychotic disorder was entered in all multivariable models as a control variable. Interaction terms were not examined because the main effects model fitted adequately and we did not have a theory-based proposition for expecting significant interactions. Multicollinearity between independent variables was assessed and was determined not to be an issue in any of the models. The fit of the models was assessed using Hosmer and Lemeshow's goodness of fit statistic.

None of the variables contained $5 \%$ or more missing values, except for the CSI variable, which contained $8 \%$ of missing data. Missing data for the CSI were replaced with individual participants' average item score as long as the respondent answered at least 9 of the 14 items. A complete case analysis was used for handling the rest of the missing data in multivariable models. Reliability statistics of the scales were assessed using the Cronbach alpha. All analyses were done using IBM SPSS Statistics v.20 for Windows. The significance level of $P<0.05$ was used throughout the study, though borderline level of significance of $P<0.06$ was also reported.

\section{Results}

The sample's socio-demographic characteristics are presented in Table 1 . Roughly $80 \%$ of the respondents had clinically significant mental health symptoms (CSI score $\geq 30$ ). Nearly two-thirds of the sample had experienced high severity of lifetime substance use problems. Similar to previous studies that reported high rates of concurrent psychiatric and substance use disorders among homeless people $[48,49]$, as many as $54 \%$ (not reported in Table 1) of our sample had both severe psychiatric illness and severe substance use problems. Of the total sample, $36 \%$ of individuals were found to have a current psychotic disorder. Although the majority of respondents had a regular medical doctor (66\%), a usual source of outpatient care $(90 \%)$, and a provincial health card (93\%), 40\% reported unmet healthcare needs.

The prevalence of the various types of discrimination experienced within healthcare settings in the past 12 months is presented in Table 2. Overall, $42 \%$ of respondents reported at least one form of perceived discrimination (not reported in Table 2). After grouping variables in the three categories of interest, the most prevalent forms of perceived discrimination were due to mental illness/ substance use (33\%) and homelessness/poverty (30\%). Only $20 \%$ of non-White and $15 \%$ of the total participants reported discrimination due to race/ethnicity/skin color. 
Table 1 Characteristics of homeless adults with mental illness at the Toronto site of the At Home/Chez Soi project $(N=550)$

\begin{tabular}{|c|c|c|}
\hline Characteristic & & Total N (\%) \\
\hline \multirow[t]{4}{*}{ Age, y } & $<30$ years old & $131(23.8)$ \\
\hline & 30-39 years old & $129(23.5)$ \\
\hline & 40-49 years old & $176(32.0)$ \\
\hline & $\geq 50$ years old & $114(20.7)$ \\
\hline Male $e^{£}$ & & $384(69.8)$ \\
\hline \multirow[t]{3}{*}{ Race $^{\S}$} & White & $194(35.3)$ \\
\hline & Black & $190(34.5)$ \\
\hline & $\begin{array}{l}\text { Other ethnic } \\
\text { minority }\end{array}$ & $166(30.2)$ \\
\hline \multirow[t]{3}{*}{ Monthly income, CAD } & $<\$ 500$ & $198(36.0)$ \\
\hline & $\$ 500-\$ 999$ & $233(42.4)$ \\
\hline & $\geq \$ 1,000$ & $118(21.5)$ \\
\hline Homeless for $\geq 3$ years & & $287(52.2)$ \\
\hline Immigrant & & $251(45.6)$ \\
\hline Has a regular medical doctor & & $360(65.5)$ \\
\hline Has a usual source of outpatient care & & $492(89.5)$ \\
\hline Has a provincial health card & & $512(93.1)$ \\
\hline Unmet healthcare needs & & $218(39.6)$ \\
\hline $\mathrm{CSI} \geq 30^{\dagger}$ & & $427(77.6)$ \\
\hline Psychotic disorder ${ }^{\ddagger}$ & & $200(36.4)$ \\
\hline \multirow[t]{3}{*}{ GAIN SDScr (lifetime) } & No or low severity & $96(17.5)$ \\
\hline & Moderate severity & $102(18.5)$ \\
\hline & High severity & $342(62.2)$ \\
\hline \multirow[t]{3}{*}{ Hospital ER visits in the past 6 months } & No visits & $223(40.5)$ \\
\hline & 1 visit & $141(25.6)$ \\
\hline & $\geq 2$ visits & $178(32.4)$ \\
\hline
\end{tabular}

Column totals may not add to the total sample size because of missing data. ${ }^{\mathrm{E}}$ Male category includes transgender/transsexual individuals.

§Other ethnic minority category included individuals with Asian, Middle Eastern, Aboriginal, Latin American, and mixed racial/ethnic background. ${ }^{\dagger} \mathrm{CSI} \geq 30$, score $\geq 30$ on the Colorado Symptom Index indicates psychiatric disability and presence of clinically significant mental symptoms.

${ }^{\ddagger}$ MINI v. 6.0; the Mini International Neuropsychiatric Interview 6.0 .

GAIN SDScr; Global Assessment of Individual Need Short Screener. Counts are triaged into low (0 symptoms), moderate (1-2 symptoms), and high ( 3 or more symptoms) severity symptoms.

Interestingly, those who reported discrimination due to homelessness/poverty were 32 times more likely to report discrimination due to mental illness/substance use (odds ratio $(\mathrm{OR})=32.0,95 \%$ Confidence Interval $(\mathrm{CI})=19.3$ $53.2, \mathrm{P}<.001)$, and 10 times more likely to report discrimination due to race/ethnicity/skin color $(\mathrm{OR}=10.3,95 \% \mathrm{CI}$ 6.0-17.6, $\mathrm{P}<.001)$. Those who have experienced discrimination due to mental illness/substance use were almost 9 times more likely to report discrimination due to race/ethnicity/skin color $(\mathrm{OR}=8.8,95 \%$ CI 5.1 15.3, $\mathrm{P}<.001)$.
Table 2 Prevalence of perceived experience of discrimination within healthcare settings among homeless adults with mental illness at the Toronto site of the At Home/Chez Soi project $(N=550)$

\begin{tabular}{lc}
\hline Discrimination due to: & $\begin{array}{c}\text { Percentage } \\
\text { distribution, N (\%) }\end{array}$ \\
\hline Homelessness or poverty & $167(30.4)$ \\
Homelessness & $147(26.7)$ \\
Poverty & $134(24.4)$ \\
Mental health, alcohol and drug-related issues & $179(32.5)$ \\
Mental health issues & $131(23.8)$ \\
Use of alcohol or drugs & $112(20.4)$ \\
Race or ethnicity or skin color & $84(15.3)$ \\
Race & $65(11.8)$ \\
Ethnicity & $68(12.4)$ \\
Skin color & $59(10.7)$
\end{tabular}

\section{Discrimination due to poverty or homelessness within} healthcare settings

Table 3 shows the results of multivariable analysis models predicting the unadjusted and adjusted odds ratios with 95\% confidence intervals of individuals perceiving discrimination in the three domains. In the unadjusted analysis, White race (as compared to Black race), higher income, $\geq 3$ years duration of homelessness, presence of clinically significant mental health symptoms, moderate to severe substance use, and any ED visit in the past 6 months were significant determinants of perceived discrimination due to poverty or homelessness. In the adjusted model, significant independent predictors of discrimination due to poverty or homelessness were duration of homelessness $\geq 3$ years, clinically significant mental health symptoms (borderline level of significance at $\mathrm{p}<.06$ ), moderate to severe substance use problems and $\geq 2$ ED visits in the past 6 months.

\section{Discrimination due to mental illness or substance use within healthcare settings}

Participant characteristics significantly associated with reporting discrimination due to mental illness or substance use were younger age, being White (as opposed to Black or other ethnic minority), having higher income, being homeless for $\geq 3$ years, having clinically significant mental health symptoms, high severity of substance use problems, absence of psychotic disorder, and reporting any ED visits in the past 6 months (Table 3). In the adjusted model, significant predictors of perceived discrimination due to mental illness/substance use were younger age, White race, being homeless for $\geq 3$ years, having clinically significant mental health symptoms, and reporting any ED visits in the past 6 months. 
Table 3 Associations between participants' characteristics and type of perceived discrimination within healthcare settings

\begin{tabular}{|c|c|c|c|c|c|c|c|}
\hline \multirow[t]{2}{*}{ Explanatory variables } & & \multicolumn{2}{|c|}{$\begin{array}{l}\text { Discrimination due to poverty } \\
\text { or homelessness }\end{array}$} & \multicolumn{2}{|c|}{$\begin{array}{l}\text { Discrimination due to mental } \\
\text { illness or alcohol or drugs }\end{array}$} & \multicolumn{2}{|c|}{$\begin{array}{l}\text { Discrimination due to race or } \\
\text { ethnicity or skin color }\end{array}$} \\
\hline & & Unadjusted OR & Adjusted $\mathrm{OR}^{1}$ & Unadjusted OR & Adjusted $\mathrm{OR}^{2}$ & Unadjusted OR & Adjusted $\mathrm{OR}^{3}$ \\
\hline $\mathrm{Age}^{\S}$, years, mean (SD) & & $.95[.81-1.12]$ & - & $.78[.67-.92]^{* *}$ & $.70[.58-.85]^{* * *}$ & $.88[.71-1.08]$ & - \\
\hline Male ${ }^{£}$ & & $1.10[.74-1.64]$ & - & $.83[.56-1.21]$ & - & 1.13 [.68-1.90] & - \\
\hline \multirow[t]{3}{*}{ Race } & White (ref) & 1.0 & 1.0 & 1.0 & 1.0 & 1.0 & 1.0 \\
\hline & Black & $.53[.34-.83]^{* *}$ & $.72[.44-1.20]$ & $.39[.25-.60]^{* * *}$ & $.46[.28-.77]^{* *}$ & $3.13[1.66-5.91]^{* * *}$ & $3.96[1.99-7.88]^{* * *}$ \\
\hline & Other ethnic minority & $.79[.51-1.23]$ & $.94[.58-1.55]$ & $.54[.35-.85]^{* *}$ & $.53[.32-.89]^{*}$ & $2.65[1.37-5.12]^{* *}$ & $3.22[1.61-6.42]^{* *}$ \\
\hline \multirow[t]{3}{*}{ Monthly income, CAD } & $<\$ 500$ (ref) & 1.0 & 1.0 & 1.0 & 1.0 & 1.0 & - \\
\hline & $\$ 500-\$ 999$ & $1.52[.99-2.33]^{9}$ & 1.25 [.78-1.99] & $1.78[1.17-2.72]^{* *}$ & $1.47[.91-2.37]$ & $1.30[.77-2.21]$ & - \\
\hline & $\geq \$ 1,000$ & $1.78[1.08-2.92]^{*}$ & $1.42[.82-2.44]$ & $2.00[1.22-3.28]^{* *}$ & $1.50[.86-2.62]$ & $1.03[.56-2.09]$ & - \\
\hline Homeless for $\geq 3$ years & & $1.80[1.23-2.61]^{* *}$ & $1.64[1.08-2.48]^{*}$ & $1.55[1.07-2.24]^{*}$ & $1.60[1.04-2.47]^{*}$ & $1.34[.83-2.16]$ & - \\
\hline $\mathrm{CSI}^{\dagger} \geq 30$ & & $2.35[1.41-3.93]^{* *}$ & $1.75[.99-3.10]^{\pi}$ & $2.92[1.73-4.92]^{* * *}$ & $1.97[1.11-3.52]^{*}$ & $1.94[.99-3.79]^{\pi}$ & $2.16[1.03-4.55]^{*}$ \\
\hline \multirow[t]{3}{*}{ GAIN SDSCrll } & No/low (ref) & 1.0 & 1.0 & 1.0 & 1.0 & 1.0 & 1.0 \\
\hline & Moderate & $2.45[1.18-5.09]^{*}$ & $2.54[1.17-5.50]^{*}$ & $1.65[.82-3.33]$ & $1.27[.59-2.72]$ & $3.39[1.44-7.99]^{* *}$ & $3.76[1.56-9.09]^{* *}$ \\
\hline & High & $3.58[1.91-6.69]^{* * *}$ & $2.41[1.21-4.81]^{*}$ & $3.25[1.82-5.81]^{* * *}$ & $1.49[.77-2.87]$ & $1.92[.88-4.21]$ & $1.85[0.81-4.21]$ \\
\hline Psychotic disorder ${ }^{\ddagger}$ & & $.82[.56-1.20]$ & 1.04 [.68-1.60] & $.58[.39-.86]^{* *}$ & $.76[.48-1.18]$ & 1.11 [.69-1.80] & $1.02[0.60-1.73]$ \\
\hline \multirow{3}{*}{$\begin{array}{l}\text { ED visits in the past } \\
6 \text { months }\end{array}$} & No visits (ref) & 1.0 & 1.0 & 1.0 & 1.0 & 1.0 & 1.0 \\
\hline & 1 visit & $1.64[1.01-2.66]^{*}$ & $1.55[.92-2.61]$ & $2.29[1.41-3.70]^{* *}$ & $1.81[1.07-3.07]^{*}$ & $2.11[1.16-3.86]^{*}$ & $2.68[1.41-5.09]^{* *}$ \\
\hline & $\geq 2$ visits & $2.62[1.69-4.08]^{* * *}$ & $2.07[1.28-3.35]^{* *}$ & $3.43[2.20-5.35]^{* * *}$ & $2.57[1.57-4.20]^{* * *}$ & $2.02[1.13-3.58]^{*}$ & $2.55[1.37-4.76]^{* *}$ \\
\hline
\end{tabular}

$\mathrm{Cl}$, confidence interval; OR, Odds Ratio $(95 \% \mathrm{Cl})$. Presence of psychotic disorder was entered in all multivariable models as a control variable.

${ }_{5}^{5}$ Age is measured in decades in logistic regression analyses.

${ }^{2}$ Male category includes transgender/transsexual individuals.
${ }^{+} \mathrm{CSI} \geq 30$, score $\geq 30$ on the Colorado Symptom Index indicates psychiatric disability and presence of clinically significant mental symptoms.

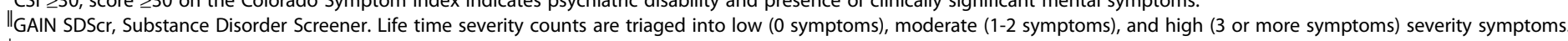

${ }^{\ddagger}$ MINI v. 6.0; the Mini International Neuropsychiatric Interview 6.0.

1 - Model coefficients: $\chi 2(11, \mathrm{n}=509)=47.79, \mathrm{P}<.001$; Hosmer\&Lemeshow test: $\chi 2(8, \mathrm{n}=509)=10.9, p=.21$.

2 - Model coefficients: $\chi 2(12, \mathrm{n}=504)=80.35, \mathrm{P}<.001$; Hosmer\&Lemeshow test: $\chi 2(8, \mathrm{n}=504)=4.91, p=.77$.

3 - Model coefficients: $\chi 2(8, \mathrm{n}=519)=41.27, \mathrm{P}<.001$; Hosmer\&Lemeshow test: $\chi 2(8, \mathrm{n}=519)=9.65, p=.29$.

${ }^{*} p<.05 ;{ }^{* *} p<.01 ;{ }^{* * *} p<.001$; Borderline significance at $p<.06$ 


\section{Discrimination due to race or ethnicity or skin color within healthcare settings}

The unadjusted analysis showed that being non-White, having clinically significant mental health symptoms, moderate lifetime severity of substance use (as compared to no or low severity of substance use problems) and having any ED visits in the past 6 months significantly increased the odds of experiencing discrimination due to race/ethnicity/skin color in the past 12 months (Table 3). All the associations remained significant in the adjusted model. We used sensitivity analysis to examine robustness of the predictors for the race/ethnicity/skin color discrimination in the subsample of non- White participants $(n=329)$ as their experiences of this form of discrimination will be inherently different from the White counterparts (see Table 4). In the sensitivity analysis, no significant differences were observed between Blacks and other ethnic minorities with regard to the discrimination due to race/ethnicity/skin color within healthcare settings. Both moderate lifetime severity of substance use and having any ED visits in the past 6 months significantly increased the likelihood of experiencing discrimination due to race/ethnicity/skin color in the past 12 months among non-Whites. The association of clinically significant mental health symptoms with the race/ ethnicity-based discrimination was, however, not significant in this sub-sample.

\section{Discussion}

Our findings suggest that among ethnically diverse homeless adults with mental illness in a large urban center in Canada, perceived discrimination in healthcare settings is common. Perceptions of discrimination due to homelessness/poverty (30.4\%) and mental health/substance use problems (32.5\%) were more frequently reported than discrimination due to race/ethnicity/skin color (15.3\%).

Our results on the prevalence of perceived discrimination based on mental illness and alcohol or substance use are not surprising. Previous research has shown that among adults with serious mental illness, the most common grounds for self-reported discrimination is mental disability rather than discrimination due to other characteristics, such as race, gender, sexual orientation, or physical disability $[15,18]$. In 2004, the Standing Senate Committee on Social Affairs, Science and Technology of Canada recognized the widespread stigma and discrimination associated with mental illness in all walks of Canadian society and acknowledged that combating discrimination "requires a multi-pronged effort sustained over a long period of time" [50] (Chapter 4, Section 4.1, p. 25).

We similarly found a high prevalence of perceived discrimination due to homelessness and poverty in healthcare settings in our sample. Discrimination towards homeless people, particularly those with concurrent mental illness, has not been widely studied. Homelessness as a marker of social status and extreme poverty may lead to more perceived discrimination than race/ethnicity. Not surprisingly, we found a higher prevalence of discrimination due to poverty or homelessness among individuals who have been homeless for three years or longer, suggesting that stigmatizing attributes of homelessness become more salient over time.

Although over two thirds of sample was non-White, discrimination due to race/ethnicity/skin color was reported by only $15 \%$ of the participants. Previous research has shown that people living with serious mental illness tend to report less discrimination due to race compared to discrimination associated with mental disability $[15,18]$. Studies have also documented that perceived everyday racial discrimination is significantly underreported by individuals who belong to lower socioeconomic status [51,52]. Another plausible explanation of these findings is that most race-based discriminatory encounters in Canada today are subtle, elusive, or systemic relative to traditionally overt forms, and may be more difficult for individuals to identify or reconcile $[53,54]$.

Individuals who experienced discrimination due to homelessness/poverty were significantly more likely to report discrimination due to mental illness/substance use. Stigma and discrimination due to mental illness are known to perpetuate a cycle of impoverishment $[24,25]$. Mental illness and homelessness may be two highly salient and overlapping social identities in our sample. A higher reporting of discrimination due to poverty/homelessness and mental illness/substance use among individuals with mental illness who have been homeless for three years or longer confirms the interrelatedness of these marginalized social statuses. Furthermore, a considerable psychosocial stress associated with homelessness makes it difficult to disentangle issues experienced by homeless people with mental illness from those of the homeless population at large [55]. A greater understanding of perceived discrimination related to the unique experiences of homeless people will require research that looks at multiple types and compound effects - of discrimination and its health effects.

The self-reported experiences of discrimination across all three domains were significantly associated with the severity of mental health problems and ED utilization in adjusted models. Previous research has suggested that the stigma of mental illness may be perceived differently depending on the severity of mental illness [56]. Severity of mental illness is accompanied by different characteristics of psychosocial disability noticeable to the public (e.g. violent behaviour or homelessness). Therefore, the lay perception of people with mental illness is influenced by their psychosocial disabilities, which have differential 
Table 4 Associations between participants' characteristics and race/ethnicity based discrimination within healthcare settings among non-White participants

\begin{tabular}{|c|c|c|c|}
\hline \multirow[t]{2}{*}{ Explanatory variables } & & \multicolumn{2}{|c|}{ Discrimination due to race or ethnicity or skin color $(n=329$} \\
\hline & & Unadjusted OR & Adjusted $\mathrm{OR}^{3}$ \\
\hline $\mathrm{Age}^{\S}$, years, mean (SD) & & $.94[.75-1.18]$ & - \\
\hline Male & & $1.07[.61-1.90]$ & - \\
\hline \multirow[t]{2}{*}{ Race } & Black (ref) & 1.0 & - \\
\hline & Other ethnic minority & $.84[.50-1.44]$ & - \\
\hline \multirow[t]{3}{*}{ Monthly income, CAD } & $<\$ 500$ (ref) & 1.0 & 1.0 \\
\hline & $\$ 500-\$ 999$ & $1.80[.98-3.32]$ & $1.54[.79-3.00]$ \\
\hline & $\geq \$ 1,000$ & $1.96[.94-4.09]$ & $1.87[.83-4.19]$ \\
\hline Homeless for $\geq 3$ years & & $1.57[.92-2.68]$ & $1.54[.85-2.80]$ \\
\hline $\mathrm{CSI}^{\dagger} \geq 30$ & & $1.69[.84-3.41]$ & $1.67[.75-3.70]$ \\
\hline \multirow[t]{3}{*}{ GAIN SDScrll } & No/low (ref) & 1.0 & 1.0 \\
\hline & Moderate & $3.61[1.43-9.13]^{* *}$ & $3.66[1.39-9.61]^{* *}$ \\
\hline & High & $2.82[1.20-6.60]^{*}$ & $1.75[.70-4.38]$ \\
\hline Psychotic disorder ${ }^{\neq}$ & & $.97[.57-1.67]$ & $1.05[0.58-1.89]$ \\
\hline \multirow[t]{3}{*}{ ED visits in the past 6 months } & No visits (ref) & 1.0 & 1.0 \\
\hline & 1 visit & $2.68[1.38-5.19]^{*}$ & $3.17[1.56-6.48]^{* *}$ \\
\hline & $\geq 2$ visits & $2.58[1.34-4.96]^{*}$ & $2.27[1.13-4.55]^{*}$ \\
\hline
\end{tabular}

The adjusted model includes variables that were associated with the outcome variable at the level of $\mathrm{P} \leq .20$ in the univariate analysis and presence of psychotic disorder as a control variable.

$\mathrm{Cl}$, confidence interval; OR, Odds Ratio (95\% Cl).

${ }^{\S}$ Age is measured in decades in logistic regression analyses.

${ }^{\mathrm{f}}$ Male category includes transgender/transsexual individuals

${ }^{+} \mathrm{CSI} \geq 30$, score $\geq 30$ on the Colorado Symptom Index indicates psychiatric disability and presence of clinically significant mental symptoms.

GAIN SDScr; Substance Disorder Screener. Counts are triaged into low (0 symptoms), moderate (1-2 symptoms), and high (3 or more symptoms)

severity symptoms.

${ }^{\ddagger} \mathrm{MINI}$ v. 6.0; the Mini International Neuropsychiatric Interview 6.0.

Model coefficients: $\chi 2(9, \mathrm{n}=329)=27.24, \mathrm{P}<.01$; Hosmer\&Lemeshow test: $\chi 2(8, \mathrm{n}=329)=4.28, p=.83$.

${ }^{*} p<.05 ;{ }^{* *} p<.01 ;{ }^{* * *} p<.001$.

impact on the degree of perceived stigma accompanying the disease [56]. A lack of respectful treatment by general practitioners and ED clinicians have been reported as the most common complaint among people with mental illness in Canada [57].

Individuals with more severe lifetime substance use problems were significantly more likely to report discrimination due to homelessness/poverty and race/ethnicity/ skin color in healthcare settings, even after adjusting for socio-demographic characteristics, severity of mental illness and frequency of ED visits.

Interestingly, the severity of lifetime substance use problems was not associated with the likelihood of perceived discrimination due to mental illness/substance use. It has been suggested that substance use is a way of coping with stressful life events and the chronic stressors of homeless life [58] and racism [59]. Substance use itself in this population group may not be perceived as stigmatizing, but rather a component of the homeless subculture [60]. In this study, discrimination due to mental illness/substance use was more prevalent among younger Whites. These findings point to a greater need for additional consideration of race and age in future research on perceived stigma and discrimination.

Individuals who perceived discrimination due to race/ ethnicity/skin color within healthcare settings were more likely to be non-White, have moderate severity of lifetime substance use problems, and report ED use in the past 6 months. Duration of homelessness, as expected, did not affect the likelihood of reporting race/ethnicity-based discrimination. In our study, sensitivity analyses showed that perceived discrimination due to race/ethnicity/skin color may be differentially biased among White participants compared to non-Whites, and likely explained the original association between the race/ethnicity-based discrimination and CSI score in the total sample.

Overall, our study revealed that individuals who experienced discrimination in one domain were more likely to report discrimination in the other two domains and supports the need for an intersectional theoretical framework [55,61-64] in future research. A cumulative effect of various types of discrimination could be especially detrimental for individuals who belong to multiple stigmatizing social identities, like those in our study sample. Future research 
is needed to examine the cumulative impact of multiple dimensions of perceived discrimination on individual health and wellbeing.

High unmet healthcare needs despite relatively good indicators of access to healthcare (having a usual source of outpatient care, a regular medical doctor and a provincial health card) identified in this population suggest that discrimination may be an important determinant of access to healthcare among disadvantaged patients. High prevalence of unmet healthcare needs in this sample is supported by previous studies of homeless individuals with mental illness [20,21]. Past research has also established that health service underutilization among homeless people is related to perceived stigma and negative perceptions of service staff (e.g. [9,10,65-70]). Intense emotional responses to these experiences can greatly influence homeless individuals' willingness to seek healthcare in the future [10]. Focused efforts to assess and improve healthcare providers' attitudes towards homeless people have been proposed to address this issue [71]. Future research should further explore the associations between perceived discrimination and unmet healthcare needs within the setting of universal health coverage and good healthcare access.

Important limitations of our study are the crosssectional and observational nature of the data that precludes us from making inferences regarding cause and effect. It is possible that our research has the same-source bias. This could have generated erroneous associations due to the correlated measurement error or because the outcome affects the perception (e.g. self-reported ED visits and perceived discrimination in healthcare settings). Furthermore, the recall of healthcare utilization among homeless persons has been reported as less accurate than the general public [72]. In our study perceived discrimination was a subjective measure rather than observable acts of discrimination. We did not collect information on the frequency and extent of perceived discrimination, e.g. minor incidents or serious assaults. In addition, a larger representative sample of sexual minorities will be needed to allow comparisons of transgender/transsexual individuals with other groups.

The strengths of the study include the use of a large sample of racially diverse homeless adults with mental illness, and rich information on perceptions of discrimination and measures of mental health and substance use, which allowed us to address some of the gaps and limitations in previous research. We explored perceived discrimination within healthcare settings related to poverty, homelessness, mental illness, substance use, race, ethnicity, and skin color, which are particularly relevant for this vulnerable population. To the best of our knowledge, this is the first such study in Canada. The associations we established, while not necessarily causal, help build a detailed picture of discrimination experienced by homeless people in contemporary Canada. Future research, preferably using longitudinal data, is needed to provide a better assessment of the direction and strength of the causal paths in the reciprocal relationships between perceived discrimination within healthcare settings, aspects of mental health status, and healthcare utilization.

\section{Conclusion}

In our sample of homeless individuals with severe mental illness, perceived discrimination due to marginalized social status was associated with a greater severity of lifetime substance abuse and mental health problems and more frequent ED use. There is an urgent need for public health policies and strategies geared toward minimizing discrimination associated with mental illness and devalued socio-economic status in order to enhance equitable access to medical treatment and other health services.

\section{Endnotes}

${ }^{\mathrm{a}} \mathrm{A}$ more detailed definition is described in Goering et al. (2011).

\section{Abbreviations \\ CSI: Colorado Symptom Index; ED: Emergency Department; GAIN-SS: Global Assessment of Individual Need Short Screener; SDScr: Substance Disorder Screener; SES: Socio-economic status; MINI: Mini International \\ Neuropsychiatric Interview.}

\section{Competing interests}

The authors declare that they have no competing interests.

\section{Authors' contributions}

AS carried out planning of the study, execution, editing, revision, data analysis, and data interpretation. PO and CC participated in the design of the study, planning, revision, data analysis and interpretation. SZ contributed to planning, drafting the manuscript, and data interpretation. SG was involved in manuscript revisions and data interpretation. VS conceived the study, and participated in its planning, design, coordination, execution, revisions, editing, data interpretation, and overall supervision of the project. All authors read and approved the final manuscript.

\section{Acknowledgements}

We also thank Jayne Barker (2008-11), Ph.D., Cameron Keller (2011-12), and Catharine Hume (2012-present) Mental Health Commission of Canada At Home/Chez Soi National Project Leads, Paula Goering, Ph.D. The National Research Lead, the National Research Team, the five site research teams, the Site Coordinators, and the numerous service and housing providers, as well as persons with lived experience, who have contributed to this project and the research. This research has been made possible through a financial contribution from Health Canada. The views expressed herein solely represent the authors. We declare that there is no conflict of interest.

\section{Author details}

'Centre for Research on Inner City Health, Li Ka-Shing Knowledge Institute, Keenan Research, Centre, St. Michael's Hospital, Toronto, Canada. ${ }^{2}$ Dalla Lana School of Public Health, University of Toronto, Toronto, Canada. ${ }^{3}$ Toronto People with Lived Experience Caucus, Toronto Local Advisory Committee, National Consumer Panel, Toronto, Canada. ${ }^{4}$ Department of Psychiatry, University of Toronto, Toronto, Canada. 
Received: 6 October 2013 Accepted: 1 September 2014

Published: 7 September 2014

\section{References}

1. Meyer IH: Prejudice as stress: Conceptual and measurement problems. Am J Public Health 2003, 93(2):262-265.

2. Williams DR, Yu Y, Jackson JS, Anderson NB: Racial Differences in Physical and Mental Health: Socioeconomic Status, Stress, and Discrimination. J Health Psychol 1997, 2(3):335-351.

3. Krieger N: Discrimination and health. In Social epidemiology. Edited by Kawachi I, Berkman L. Oxford: Oxford University Press; 2000:36-75.

4. Paradies Y: A systematic review of empirical research on self-reported racism and health. Int J Epidemio/ 2006, 35(4):888-901.

5. Williams DR, Neighbors HW, Jackson JS: Racial/Ethnic Discrimination and Health: Findings From Community Studies. Am J Public Health 2008, 98(SUP1):S29-S37.

6. Kessler RC, Mickelson KD, Williams DR: The prevalence, distribution, and mental health correlates of perceived discrimination in the United States. J Health Soc Behav 1999, 40:208-230.

7. Thornicroft G, Rose D, Kassam A, Sartorius N: Stigma: ignorance, prejudice or discrimination? Br J Psychiatry 2007, 190(3):192-193.

8. Bungay V, Johnson JL, Varcoe C, Boyd S: Women's health and use of crack cocaine in context: structural and'everyday'violence. Int J Drug Policy 21(4):321.

9. Martins DC: Experiences of homeless people in the health care delivery system: a descriptive phenomenological study. Public Health Nurs 2008, 25(5):420-430.

10. Wen CK, Hudak PL, Hwang SW: Homeless peoples' perceptions of welcomeness and unwelcomeness in healthcare encounters. J Gen Intern Med 2007, 22(7):1011-1017.

11. Thornicroft G, Rose D, Kassam A: Discrimination in health care against people with mental illness. Int Rev Psychiatry 2007, 19(2):113-122.

12. Nestel S: Colour Coded Health Care: The Impact of Race and Racism on Canadians' Health. In. Wellesley Institute: Toronto, ON; 2012.

13. Pascoe E, Richman L: Perceived discrimination and health: A meta-analytic review. Psychol Bull 2009, 135(4):531-554.

14. Shavers VL, Klein WMP, Fagan P: Editorial: Research on Race/Ethnicity and Health Care Discrimination: Where We Are and Where We Need to Go. Am J Public Health 2012, 102(5):930-932.

15. Corrigan P, Thompson V, Lambert D, Sangster Y, Noel JG, Campbell J: Perceptions of discrimination among persons with serious mental illness. Psychiatr Serv 2003, 54(8):1105-1110.

16. Minior T, Galea S, Stuber J, Ahern J, Ompad D: Racial differences in discrimination experiences and responses among minority substance users. Ethn Dis 2003, 13(4):521-527.

17. Young M, Stuber J, Ahern J, Galea S: Interpersonal discrimination and the health of illicit drug users. Am J Drug Alcohol Abuse 2005, 31(3):371-391.

18. Thompson VLS, Noel JG, Campbell J: Stigmatization, discrimination, and mental health: the impact of multiple identity status. Am J Orthopsychiatry 2004, 74(4):529-544

19. Conner KO, Rosen D: "You're nothing but a junkie": Multiple experiences of stigma in an aging methadone maintenance population. J Soc Work Pract Addict 2008, 8(2):244-264.

20. Baggett TP, O'Connell JJ, Singer DE, Rigotti NA: The unmet health care needs of homeless adults: a national study. Am J Public Health 2010, 100(7):1326-1333.

21. Hwang SW, Ueng JJM, Chiu S, Kiss A, Tolomiczenko G, Cowan L, Levinson W, Redelmeier DA: Universal Health Insurance and Health Care Access for Homeless Persons. Am J Public Health 2010, 100(8):1454-1461.

22. Kushel MB, Vittinghoff E, Haas JS: Factors associated with the health care utilization of homeless persons. JAMA 2001, 285(2):200-206.

23. Schulze B, Angermeyer MC: Subjective experiences of stigma. A focus group study of schizophrenic patients, their relatives and mental health professionals. Soc Sci Med 2003, 56(2):299.

24. Stuart H: Fighting stigma and discrimination is fighting for mental health. Canadian Public Policy 2005, 31(s1):21-28.

25. Hulchanski JDC, Chau P, Hwang S, Paradis SE: Canadian Population Health Initiative of the Canadian Institute for Health Information: Mental Health, Mental IIIness, and Homelessness in Canada. In Finding Home: Policy Options for Addressing Homelessness in Canada (e-book), Chapter 2.3. Edited by Hulchanski JDC, Chau P, Hwang S, Paradis SE. Toronto, ON: Cities Centre Press, University of Toronto; 2009.

26. Aday LA: At risk in America: The health and health care needs of vulnerable populations in the United States. 2nd edition. San Francisco, CA: John Wiley \& Sons; 2001.

27. Hwang S, Stergiopoulos V, O'Campo P, Gozdzik A: Ending homelessness among people with mental illness: the At Home/Chez Soi randomized trial of a Housing First intervention in Toronto. BMC Public Health 2012, 12(1):787.

28. Goering PN, Streiner DL, Adair C, Aubry T, Barker J, Distasio J, Hwang SW, Komaroff J, Latimer E, Somers J: The At Home/Chez Soi trial protocol: a pragmatic, multi-site, randomised controlled trial of a Housing First intervention for homeless individuals with mental illness in five Canadian cities. BMJ open 2011, 1(2). 2 e000323 doi:10.

29. Sheehan DV, Lecrubier $Y$, Sheehan KH, Amorim P, Janavs J, Weiller E, Hergueta T, Baker R, Dunbar GC: The Mini-International Neuropsychiatric Interview (MINI): the development and validation of a structured diagnostic psychiatric interview for DSM-IV and ICD-10. I Clin Psychiatry 1998, 59(Suppl 20):22-33.

30. Crowe C, Hardill K: Nursing research and political change: the street health report. Can Nurse 1993, 89(1):21-24.

31. Khandor E, Mason K: The street health report 2007. Creative Commons: Toronto, ON; 2007

32. 2006 Census of Population. [http://www12.statcan.gc.ca/censusrecensement/2006/index-eng.cfm]

33. Yau M, O'Reilly J: 2006 Student Census, Grades 7-12: System Overview Toronto. Report No. 07/08-01. Toronto, ON: Toronto District School Board; 2007.

34. Goering P: Making a Difference: Ontario's Community Mental Health Evaluation Initiative. Canadian Mental Health Association: Toronto, ON; 2004.

35. Shern DL, Wilson NZ, Coen AS, Patrick DC, Foster M, Bartsch DA, Demmler J: Client outcomes II: Longitudinal client data from the Colorado treatment outcome study. Milbank Q 1994, 72(1):123-148.

36. Boothroyd RA, Chen HJ: The psychometric properties of the Colorado Symptom Index. Adm Policy Ment Health and Ment Health Serv Res 2008, 35(5):370-378.

37. Conrad KJ, Yagelka JR, Matters MD, Rich AR, Williams V, Buchanan M: Reliability and validity of a modified Colorado Symptom Index in a national homeless sample. Ment Health Serv Res 2001, 3(3):141-153.

38. Greenwood RM, Schaefer-McDaniel NJ, Winkel G, Tsemberis SJ: Decreasing psychiatric symptoms by increasing choice in services for adults with histories of homelessness. Am J Community Psychol 2005, 36(3):223-238.

39. Sheehan $D V$, Lecrubier $Y$, Sheehan $K H$, Amorim $P$, Janavs J, Weiller $E$, Hergueta T, Baker R, Dunbar GC: The Mini-International Neuropsychiatric Interview (MINI): the development and validation of a structured diagnostic psychiatric interview for DSM-IV and ICD-10. J Clin Psychiatry 1998, 59:22-33.

40. Amorim P, Lecrubier Y, Weiller E, Hergueta T, Sheehan D: DSM-IH-R Psychotic Disorders: procedural validity of the Mini International Neuropsychiatric Interview (MINI). Eur Psychiatry 1998, 13(1):26-34.

41. Lecrubier Y, Sheehan D, Weiller E, Amorim P, Bonora I, Harnett Sheehan K, Janavs J, Dunbar G: The Mini International Neuropsychiatric Interview (MINI). A short diagnostic structured interview: reliability and validity according to the CIDI. Eur Psychiatry 1997, 12(5):224-231.

42. Sheehan D, Lecrubier Y, Harnett Sheehan K, Janavs J, Weiller E, Keskiner A, Schinka J, Knapp E, Sheehan M, Dunbar G: The validity of the Mini International Neuropsychiatric Interview (MINI) according to the SCID-P and its reliability. Eur Psychiatry 1997, 12(5):232-241.

43. Dennis ML, Chan YF, Funk RR: Development and validation of the GAIN Short Screener (GSS) for internalizing, externalizing and substance use disorders and crime/violence problems among adolescents and adults. Am J Addict 2006, 15(s1):S80-s91.

44. Dennis ML, Titus JC, White M, Unsicker J, Hodgkins D: Global Appraisal of Individual Needs (GAIN): Administration Guide for the GAIN and Related Measures, version 5. Bloomington, IL. In.: Chestnut Health Systems; 2006.

45. Hwang SW, Chambers C, Chiu S, Katic M, Kiss A, Redelmeier DA, Levinson W: A comprehensive assessment of health care utilization among homeless adults under a system of universal health insurance. Am J Public Health 2013, 103(S2):S294-S301.

46. Kushel MB, Perry S, Bangsberg D, Clark R, Moss AR: Emergency department use among the homeless and marginally housed: results from a community-based study. Am J Public Health 2002, 92(5):778-784. 
47. Han B, Wells BL: Inappropriate emergency department visits and use of the Health Care for the Homeless Program services by homeless adults in the northeastern United States. J Public Health Manag Pract 2003, 9(6):530-537.

48. Dennis DL, Buckner JC, Lipton FR, Levine IS: A decade of research and services for homeless mentally ill persons: Where do we stand? Am Psychol 1991, 46(11):1129-1138.

49. Stein JA, Gelberg L: Homeless men and women: Differential associations among substance abuse, psychosocial factors, and severity of homelessness. Exp Clin Psychopharmacol 1995, 3(1):75-86.

50. Parlament of Canada: The Standing Senate Committee on Social Affairs, Science and Technology, Mental Health, Mental Illness and Addiction. Interim Report, Mental Health, Mental IIIness and Addiction: Issues and Options for Canada M, Report 3. Ottawa, ON: The Standing Senate Committee on Social Affairs, Science and Technology; 2004.

51. Borrell LN, Jacobs DR, Williams DR, Pletcher MJ, Houston TK, Kiefe Cl: Self-reported racial discrimination and substance use in the Coronary Artery Risk Development in Adults Study. Am J Epidemiol 2007, 166(9):1068-1079.

52. Kelaher M, Paul S, Lambert H, Ahmad W, Paradies Y, Davey Smith G: Discrimination and health in an English study. Soc Sci Med 2008, 66(7):1627-1636

53. Beiser M, Noh S, Hou F, Kaspar V, Rumens J: Southeast Asian refugees' perceptions of racial discrimination in Canada. Canadian Ethnic Studies 2001, 33(1):46-70.

54. Noh S, Kaspar V, Wickrama K: Overt and subtle racial discrimination and mental health: preliminary findings for Korean immigrants. Journal Information 2007, 97(7):1269-1274.

55. Hankivsky O, Christoffersen A: Intersectionality and the determinants of health: A Canadian perspective. Critical Public Health 2008, 18(3):271-283.

56. Gaebel W, Zäske H, Baumann A: The relationship between mental illness severity and stigma. Acta Psychiatr Scand 2006, 113(s429):41-45.

57. Parlament of Canada: The Standing Senate Committee on Social Affairs, Science and Technology, Mental Health, Mental IIIness and Addiction. Interim Report, Mental Health, Mental IIIness and Addiction: Overview of Policies and Programs in Canada, Report 1. Ottawa, ON: The Standing Senate Committee on Social Affairs, Science and Technology; 2004.

58. Johnson TP, Freels SA, Parsons JA, Vangeest JB: Substance abuse and homelessness: social selection or social adaptation? Addiction 1997, 92(4):437-445

59. Gerrard M, Stock ML, Roberts ME, Gibbons FX, O'Hara RE, Weng C-Y, Wills TA: Coping with racial discrimination: The role of substance use. Psychol Addict Behav 2012, 26(3):550.

60. Didenko E, Pankratz N: Substance use: Pathways to homelessness? Or a way of adapting to street life. Visions: BC's Mental Health and Addictions Journal 2007, 4(1):9-10.

61. Hankivsky O, Reid C, Cormier R, Varcoe C, Clark N, Benoit C, Brotman S: Exploring the promises of intersectionality for advancing women's health research. Int J Equity Health 2010, 9(5):1-15.

62. Crenshaw K: 'Mapping the Margins: Intersectionality, Identity Politics, and Violence against Women of Colour'. In Critical Race Theory: The Key Writings that Informed the Movement. Edited by Crenshaw K, Gotanda N, Peller G, Thomas K. New York: New York Press; 1995:357-383. 1995.

63. Ahern J, Stuber J, Galea S: Stigma, discrimination and the health of illicit drug users. Drug Alcohol Depend 2007, 88:188-196.

64. Schulz AJ, Mullings L: Intersectionality and health: an introduction. In Gender, race, class, and health: Intersectional approaches. Edited by Schulz AJ, Mullings L. San Francisco, CA: Jossey-Bass; 2006:3-20.

65. Bhui K, Shanahan L, Harding G: Homelessness and mental illness: a literature review and a qualitative study of perceptions of the adequacy of care. Int J Soc Psychiatry 2006, 52(2):152-165.

66. Kim MM, Swanson JW, Swartz MS, Bradford DW, Mustillo SA, Elbogen EB: Healthcare barriers among severely mentally ill homeless adults: Evidence from the five-site health and risk study. Adm Policy Ment Health 2007, 34(4):363-375.

67. Leipersberger T: An Investigation of Mental Health Care Delivery from Consumers' Perspectives. J Hum Behav Soc Environ 2007, 15(1):1-21.

68. Padgett DK, Henwood B, Abrams C, Davis A: Engagement and retention in services among formerly homeless adults with co-occurring mental illness and substance abuse: Voices from the margins. Psychiatr Rehabil 2008, 31(3):226-233.
69. Link BG, Struening EL, Rahav M, Phelan JC, Nuttbrock L: On stigma and its consequences: evidence from a longitudinal study of men with dual diagnoses of mental illness and substance abuse. J Health Soc Behav 1997, 38:177-190.

70. Gelberg L, Browner CH, Lejano E, Arangua L: Access to women's health care: A qualitative study of barriers perceived by homeless women. Women Health 2004, 40(2):87-100.

71. Buchanan D, Rohr L, Kehoe L, Glick SB, Jain S: Changing attitudes toward homeless people. J Gen Intern Med 2004, 19(5p2):566-568.

72. Nyamathi AM, Leake B, Gelberg L: Sheltered versus nonsheltered homeless women. J Gen Intern Med 2001, 15(8):565-572.

doi:10.1186/1472-6963-14-376

Cite this article as: Skosireva et al:: Different faces of discrimination: perceived discrimination among homeless adults with mental illness in healthcare settings. BMC Health Services Research 2014 14:376.

\section{Submit your next manuscript to BioMed Central and take full advantage of:}

- Convenient online submission

- Thorough peer review

- No space constraints or color figure charges

- Immediate publication on acceptance

- Inclusion in PubMed, CAS, Scopus and Google Scholar

- Research which is freely available for redistribution

Submit your manuscript at www.biomedcentral.com/submit
C) Biomed Central 